\title{
21 \\ Support Services For Business Networking
}

\author{
I.T. Hawryszkiewycz \\ School of Computing Science, \\ University of Technology, Sydney \\ PO Box 123 Broadway, NSW 2007 \\ AUSTRALIA \\ (Tel. +612 3301809, FAX: +6123301807 \\ e-mail: igrh@socs.uts.edu.au)
}

\begin{abstract}
This paper describes the computer communication services needed in forming networks of small businesses. It describes a method used to identify the services needed for network formation, and develops a framework that simplifies service choice. It centers network formation process made up of three stages and shows that services needed at each stage are different. It then outlines the results of a questionnaire made to indicate priorities placed on these services and describes an initial set of services based on the World Wide Web.
\end{abstract}

\section{Keywords}

Business networks, groupware, electronic commerce

\section{INTRODUCTION}

Increasing use of computer communication services has been evident in the large business sector, as for example, Sauter and others (1995) reporting increasing use of conferencing and electronic mail systems by executives in Swiss corporations, or the German Government progressively installing a system known as POLITeam (Klockner and others) to allow people in Berlin and Bonn to coordinate their work by support of folder circulation folders government offices.

The costs and expertise needed to develop and operate such computer communication systems in the past has meant that they have been mainly utilized by large organizations. These cost and expertise barriers are now dropping and such technologies are becoming more affordable to small business and medium enterprises (SME). Furthermore, improved 
interfaces associated with such systems will reduce the expertise needed to use them, thus further reducing costs and providing SMEs with new networking abilities thus helping them to participate in global trade as described by Badrinath (1994).

This paper describes a study to determine the services needed by SMEs who wish to pool their resources in joint ventures to get advantages of scale. The report is based on the business network program (BNP) supported by AusIndustry in Australia, which is similar to many found in other countries. The goal is to choose communication services that reduce the considerable coordination time overheads required of senior staff, and make it easier for them to form business networks by both shortening the time to find business partners and operate the business network. The paper describes the analysis of the requirements through a questionnaire to identify the large variety of services needed within business networks and a framework for providing information technology services to meet these services. The paper then describes a system being developed on the World Wide Web to facilitate communication in business network formation.

\section{A METHOD CHOOSING SERVICES FOR BUSINESS NETWORKS}

The method used to provide a platform of services was made up of steps shown in Figure 1 and described in detail elsewhere (Hawryszkiewycz, 1996). It starts with analysis of existing work practices through participation, interviewing and questionnaires producing a set of scenarios and rich pictures as proposed in soft systems methodologies by Checkland and Scholes (1990). The process follows the traditional sequence of physical analysis, logical analysis, logical design and physical design and includes a conceptual set of terms to describe collaboration together with a rationale for choosing services.

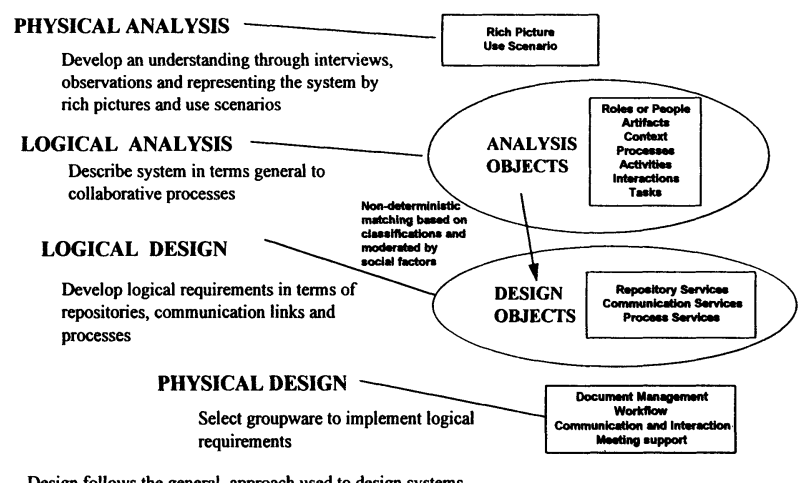

Design follows the general approach used to design systems

Figure 1 - Method Overview

Figure 1 summarizes the goals of each phase. Logical analysis classifies user objects by a set of unambiguous concepts that are later matched to design objects. The next two phases are 
design phases, which start by specifying logical requirements and then select services to realize these logical requirements. Designers must evaluate the large number of alternative services for implementing each logical requirement. Services are classified into message distribution services, meeting services, document services, and workflow services. Service selection considers the location of people in time going beyond face to face discussion to support communication where people are separated in both time and space.

\section{IDENTIFYING BUSINESS NETWORK SERVICES}

Many countries have recognized the potential of SMEs as innovative organizations, whose full potential can often not be realized because of their small size. Consequently they have encouraged alliances between SMEs to enable them to extend both their product range and marketing strength. A number of countries and Governments now actively and financially support formation of such networks, including Norway, New Zealand, Denmark, Australia as well as Quebec and Oregon state. There are also networks aimed at specific industries, as for example, USNet in the United States, a non-profit organization with a goal of supporting Inter-Firm Collaboration in Manufacturing.

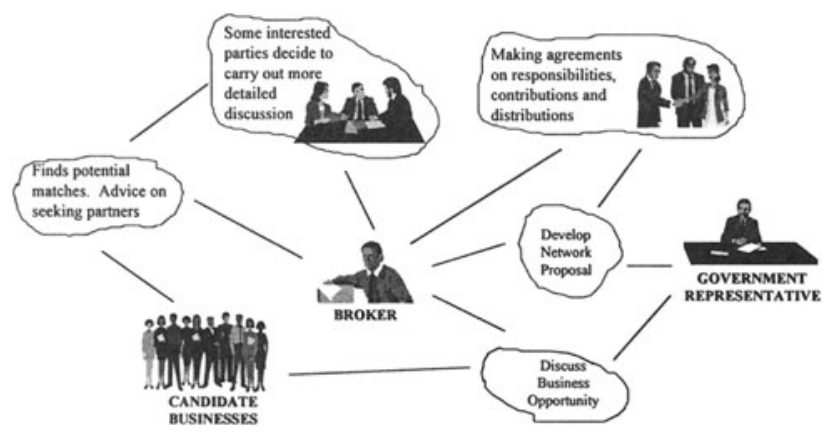

Figure 2 - Business Network Formation

Figure 2 is a top-level view typical networking program looks like. This figure uses the idea of rich pictures from soft systems methodologies (Checkland and Scholes, 1993) to describe the roles and interactions of the program. It emphasizes roles, illustrated by people icons, and interactions, illustrated by clouded items. One of the critical roles here is that of the broker. Brokers identify networking opportunities for networking and find existing SMEs to form networks to take up these opportunities. They also play an extremely important role of maintaining trust and confidentiality between potential network partners, who can often be competitors and do not want to expose themselves publicly as seeking network support. Instead they can express their need to the broker who then confidentially searches for partners. The broker initially identifies the partners anonymously and then helps them to agree on network structure and their responsibilities, contributions and expectations from the network. Brokers also help to set up any necessary business arrangements, but once set up the 
network continues to operate without further broker assistance. The role of the Government representative or network sponsor is to provide financial support when required conditions are met.

\subsection{The Network Formation Processes}

Process studies carried out by the Norwegian Business Network Program (Mjelve, 1993) have defined a network formation process applicable to any kind of network irrespective of its ultimate network operation. This process is made up of the following three stages:

Phase $0-1$ where a business understand its needs and identify potential market areas and strategy and the opportunities in the marketplace, seeks partners,

Phase 2 where the goal of the business network is clarified and a business plan drawn up, and

Phase 3 Establishment, operation and eventual expansion or termination.

Each of these phases concludes with a formal document. Initially a letter of intent is drawn up. If this is supported by the program, then more detailed planning commences to produce a cooperation agreement and a business plan. Each phase has different activities, that will require different kinds of communication support.

\subsection{Impact of the Nature of Information}

Analysis indicated that during the network formation process, information is gradually reduced from seemingly unrelated items of information, into firmer and firmer structures as a network is formed as one proceeds through the network formation stages. Initially the environment initially is made up of a collection of seemingly unrelated information about opportunities and businesses. The goal is to search through this information, reducing it to a number of working networks, based on structured information.

A similar change in the nature of information has been given by Harem (1995), who makes a distinction on grounds of richness of information. Harem work was in the context of a bidding process where richer information is needed in the process of bid formation as a wide search for expertise is made, and richer forms are needed as the proposal is written and questions answered. These less rich forms in final evaluation can be supported by services such as email. During the richest communication is face to face where meaning itself can be defined during the conversation. Information becomes less rich as it enters more constrained communication channels that impose meaning through structuring information..

\subsection{Implications on Information Technologies}

The changing nature of information has a considerable impact on the kind of service needed in each network formation phase. Phase 0 services can be based on public networks such as Internet and require descriptive data bases that are relatively unstructured and include collections of opportunities expressed in a variety of ways ranging from verbal statements to 
marketing databases. Phase 1 requires repositories become more structured and confidential in the initial exchange as issues are raised and discussion points made on the issues calling for services to support such structured discussion. Such discussion support is also required in phase 2, whereas phase 3, implementation, calls for workflow coordination tools.

\section{A FRAMEWORK FOR BUSINESS SERVICES}

The next step is to identify the business services needed to support network formation. Figure 3 shows a framework that we have developed for services within the business networking environment. The main distinction is between communication services that simplify information interchange, the advisory services and the task services specialized to each phase. The first two phases appear separately in Figure 3 because of their different activities. Phase 0 is more concerned with identifying opportunity and identifying potential partners. Phase 1 concerns discussion with potential partners. Communication initially is widespread and unstructured as a search for partners takes place. Communication, however, becomes more structured once potential partners have been identified and have to resolve specific issues.

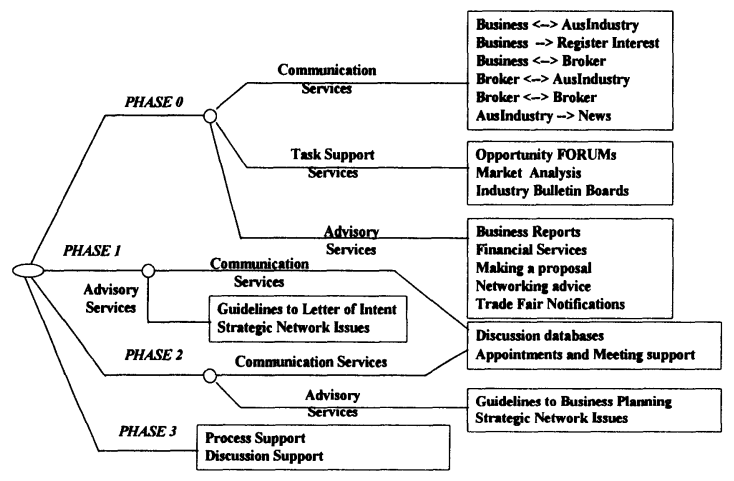

Figure 3 - Required Business Services

\subsection{Setting Priorities}

A questionnaire was conducted to determine the type of business services that brokers would find useful and their priorities, as well as the kinds of general communication support that they need. Some interviews and observations were also made on existing networks to identify the broad range of services needed to support networks. The questionnaire included questions on all categories described in Figure 3. The results are summarized following:

General Attitude - The first set of questions was an assessment of the factors that would be important in deciding whether to participate in networking. Respondents attached the most importance to easier access to product/service information, reducing time needed for networking, improving market access and improving quality of service. 
Particular Phase Needs - The table in Figure 5 summarizes the issues identified as important in the questionnaire. In summary, the questionnaire indicated strong support for systems that easily identify potential markets and business opportunities and then provide sales leads in later networking stages. Support in finding partners was also indicated although there was little support for guidelines and advice for network planning with the exception of a marketing plan. In operation, there was support for keeping track of client needs and satisfaction and for service provision.

\begin{tabular}{|c|c|c|c|}
\hline & $\begin{array}{l}\text { COMMUNI- } \\
\text { CATION }\end{array}$ & ADVISORY & TASK RELATED \\
\hline PHASE 0 & \multirow{2}{*}{$\begin{array}{l}\text { - Contacts for business } \\
\text { opportunities } \\
\text { - Contact for partners } \\
\text { - Discussion on Market } \\
\text { and Business Trends } \\
\end{array}$} & \multirow[t]{2}{*}{$\begin{array}{l}\text { - Potential Markets } \\
\text { - Business } \\
\text { Networking }\end{array}$} & - Marketing \\
\hline PHASE 1 & & & $\begin{array}{l}\text { - Matching partners } \\
\text { - Preparing letter of } \\
\text { intent }\end{array}$ \\
\hline PHASE 2 & $\begin{array}{l}\text { Issues Forum on } \\
\text { Network } \\
\text { Clarification }\end{array}$ & $\begin{array}{l}\text { - Guidelines for } \\
\text { Marketing and } \\
\text { Business Plan }\end{array}$ & $\begin{array}{l}\text { - Preparing } \\
\text { Business Plan } \\
\text { - Exchange on } \\
\text { network needs } \\
\end{array}$ \\
\hline PHASE 3 & $\begin{array}{l}\text { - Sales leads } \\
\text { - Client monitoring } \\
\text { - Exchange } \\
\text { Technical Data } \\
\end{array}$ & & $\begin{array}{l}\text { - Coordination for } \\
\text { service provision }\end{array}$ \\
\hline
\end{tabular}

Figure 5 Summary of Important Needs

Carrying on Everyday Business - This covered the everyday activities of business communication. Four issues were strongly supported involved the scheduling of meetings, forming a letter of intent and facilitating agreement on information sharing. There was also support for reaching agreement on information sharing and on developing the letter of intent. There was little support for negotiation support through information technology.

\section{SUPPORTING THE EARLY PHASES}

Our initial step is to support the early network formation stages to familiarize people with the idea of networking and provide them with assistance in taking these early steps. Much of this support has often come using the World Wide Web. Our approach in the study is to provide a service that concentrates on three aspects, namely:

- providing easy access to factual information about networks,

- providing guidelines on the network formation process especially on the support available from AusIndustry for this purpose, and

- keeping people posted with the latest news items as well as tips on what has been found to be effective.

\subsection{Using the World Wide Web}

There are now many examples of the use of World Wide Web. A large number of advisory services are now provided as for example, the NCMS (National Center for Manufacturing 
Sciences) is being set up with the specific mission of improving the manufacturing competitiveness of its member companies (see http://www.ncms.org) by supporting rapid interchange and dissemination of new developments with the goal of gaining competitive advantage through the next-generation manufacturing technologies. The US government also provides an advisory service for small businesses (see http://www.commerce.gov). Another example is the BOIS (Business opportunities Intelligence Services) system being set up by GATT (see http://faw.uni-ulm.de/BOIS/) to assist underdeveloped countries to participate in world wide trade.

\subsection{A Network Support System}

Our initial step is to provide World Wide Web (see http://linus.socs.uts.edu.au/ fthorne/bnp) to support advisory and communication services. Figure 4 illustrates a guide map that provide access to these services. Each of the boxes in Figure 4 corresponds to a selection button on the "Find your way about" World Wide Web page. The system is to provide support for:

- finding what networking is all about and information about the BNP program, including supported government programs,

- contacts to brokers, BNP officers, and latest news about the BNP,

- an opportunities page and access to marketing databases, and

- access to latest research findings,

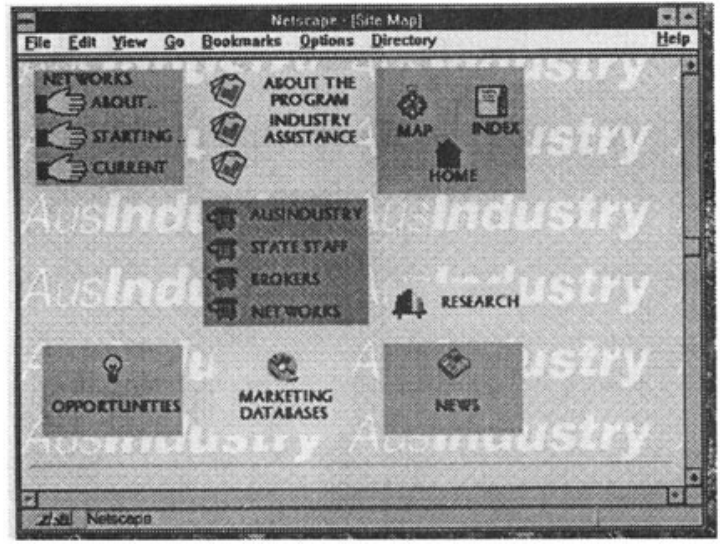

Figure 4 - BNP Services

A number of scenarios can be supported using this site. The simplest scenario is distribution of information from AusIndustry through the BNP news service. New announcements can be easily posted to brokers connected to the service. Another scenario is for a network broker or AusIndustry officer to enter an opportunity. Other brokers or state management can bring this to the attention of their client businesses. The network broker can then exchange comments 
with other brokers or even businesses on how to take advantage of the opportunity. Still another scenario is where a new user makes an enquiry about the BNP and then decides that there is some advantage in participating. One way to begin is the advisory section on the network formation process. This identifies the steps followed in network formation and provides advice for each step. The simplest advice, for example, for looking for opportunities would be to contact a broker, although it is also proposed to have an opportunities forum for this purpose. Our next step is to provide a matching service to assist in finding business partners. Further improvements to the communication services are also being planned.

\section{CONCLUSIONS}

This paper described the kinds of services available through the information highway for use by small business. It described some examples of the use of these services and described a system being developed as part of the AusIndustry research program to assist small business to form business networks.

\section{ACKNOWLEDGMENTS}

Work Described here has been supported by AusIndustry through a Grant into the Theory and Practice of Business Networks. The contribution of Fiona Thorne to the design and development of WWW pages described here is also acknowledged.

\section{REFERENCES}

Badrinath (1994): "Helping small and medium size firms to enter export markets" International Trade FORUM, 2/1994. pp. 4-29.

Checkland, P.B. and Scholes, J. (1990): Soft Systems Methodology in Action Chichester, John Wiley and Sons.

Harem, T. (1995): "Communication Technology, Knowledge Transfer and Network Transformation" European Conference on Information Systems, Athens.

Hawryszkiewycz, I.T.: (June, 1996): "A Design Method for Choosing Services for Large Distributed Teams" Conference on Design of Cooperative Systems, COOP'96, Juan-LesPins, France, June, 1996

Klockner, K., Mambrey, P., Sohlenkamp, M., Prinz, W., Fuchs, L., Kolvenbach, S., PankokeBabatz, U. and Syri, A. (September, 1995): "POLITeam Bridging the Gap between Bonn and Berlin for and with the Users" Proceedings of the Fourth European Conference on CSCW, pp.17-32.

Mjelve, O. (1993): "The Norwegian Network Programme - a brief presentation" Proceedings of the International Conference on Cooperation and Competitiveness Lisbon, October, 1993.

Sauter, C., Morger, O., Muhler, T., Hutchison, A. and Teufel, S. (September, 1995): "CSCW for Strategic Management" in Swiss Enterprises: An Empirical Study", in Marmolin, H., Sundblad, Y. and Schmidt, K. (editors), Proceedings of the Fourth European Conference on CSCW, pp.117-132, 